\title{
Experimental analysis and detailed micro-modeling of masonry walls subjected to in-plane shear
}

\author{
Anastasios Drougkas $^{\mathrm{a}, *}$, Pere Roca ${ }^{\mathrm{b}}$, Climent Molins ${ }^{\mathrm{b}}$ \\ ${ }^{a}$ Building Materials and Building Technology Division, Civil Engineering Department, KU Leuven, Kasteelpark Arenberg 40 Box 2448, B-3001 \\ Heverlee, Belgium \\ b Departament d'Enginyeria Civil i Ambiental, Universitat Politècnica de Catalunya, Campus Nord, Building C1, Jordi Girona 1-3, 08034 Barcelona, \\ Spain
}

\section{Introduction}

\subsection{Background}

Unreinforced masonry buildings are common in many seismic prone countries. In most cases they were built before the development of comprehensive research and the proposal of rational engineering procedures for their design. The careful observation of damages and collapses produced by recent earthquakes [1] has shown that the collapse mechanisms most prone to activate are normally the out-of-plane failures of walls, mainly due to the presence of insufficient connection between elements and lack of rigid horizontal diaphragms. Once such drawbacks are overcome by the introduction of appropriate devices, the shear walls provide to the building substantial stiffness and resistance against lateral forces [2]. For this reason, numerous research studies have been devoted to the interpretation of the in-plane failure modes observed in the experimental tests of these structural members. The comprehensive experimental programs available in the literature present both empirical and analytical approaches for the derivation of the strength of masonry shear walls [3-5]. Currently, the advent of sophisticated numerical approaches has produced different strategies for the simulation of the behavior of masonry structures [6,7]. In this context, it is considered that approaches combining both experimental and numerical studies are necessary in order to consolidate the existing knowledge and to obtain a better understanding of the complex behavior of masonry shear walls.

The numerical analysis of masonry walls subjected to in-plane shear is a problem often addressed using finite element macromodels. This simplified approach is made necessary by the often insufficient characterization of the mechanical properties of the constituent materials and the need to mitigate computational cost and geometric complexity. Analytical expressions may also be employed for the determination of the maximum shear capacity of the walls. Simplified micro-models introduce an added layer of detail, but may be ill-suited for cases in which sufficiently high levels of compressive forces are developed as to influence the apparent compressive strength of the mortar in the bed joints. Such high compressive stresses may indeed be developed in the diagonal compressive strut of masonry panels under in-plane shear. Detailed micro-modeling allows for a more in-depth analysis of the failure mode observed in shear walls under varying levels of vertical pre-stress and different boundary conditions.

The current state of the art on the numerical simulation of masonry walls subjected to in-plane shear using detailed micromodeling methods is very limited. Macro-models and simplified micro-models are far more common, but are faced with a different set of modeling uncertainties and assumptions necessary to be made for carrying out numerical analyses: the determination of the properties of masonry on a macro-scale, meaning the scale of the masonry composite, rather than on the scale of the individual materials.

\footnotetext{
* Corresponding author.

E-mail address: anastasios.drougkas@kuleuven.be (A. Drougkas).
} 


$\begin{array}{llll}\text { Notation } & & \mathrm{E}_{\mathrm{vert}} & \begin{array}{l}\text { Young's modulus in the vertical direction } \\ \text { Young's modulus in the horizontal direction }\end{array} \\ \mathrm{f}_{\mathrm{t}} & \text { tensile strength } & \mathrm{E}_{\mathrm{horz}} & \begin{array}{l}\text { Poisson's ratio } \\ \text { cohesion }\end{array} \\ \mathrm{f}_{\mathrm{flex}} & \text { flexural strength } & \mathrm{c} & \text { friction angle } \\ \mathrm{h} & \text { height of sample } & \varphi & \text { applied normal stress } \\ \mathrm{f}_{\mathrm{c}} & \text { compressive strength } & \sigma_{\mathrm{n}} & \text { peak shear stress } \\ \mathrm{f}_{\mathrm{c}, \mathrm{vert}} & \text { compressive strength in vertical direction } & \tau_{\max } & \text { wall height } \\ \mathrm{f}_{\mathrm{c}, \text { horz }} & \text { compressive strength in the horizontal direction } & \mathrm{H} & \text { wall length } \\ \mathrm{E} & \text { Young's modulus } & \mathrm{L} & \text { wall }\end{array}$

\subsection{Objectives}

The aim of the paper is twofold. Firstly, to present an experimental campaign on the in-plane strength capacity of brick masonry walls, conducted on quarter scale composite specimens. Additional results on the uniaxial compression of masonry wallettes are also included in the investigation. Secondly, to assess the ability of detailed micro-modeling approach to numerically simulate the experiments by comparing the numerical predictions with the experimental results.

The detailed micro-modeling approach is adopted as a strategy for numerical simulation, in which each masonry unit, the mortar joints and the unit-mortar interfaces are individually modeled. The micro-modeling approach is investigated according to different geometrical conditions, including 2D models in plane stress and plane strain and 3D models. In addition, a limited digression in the modeling approach is made in order to investigate the compression of masonry using meso-models, consisting of detailed micromodels with perfect bond between the units and the mortar. The detailed micro-models do not rely on the experimental or empirical determination of the properties of the masonry composite, but rather on that of the constituent materials, which is far easier to accomplish, particularly in the case of existing structures.

\section{Experimental campaign}

\subsection{Overview}

In the present research, a series of in-plane shear tests on fifteen scale walls under different levels of vertical stress, was considered $[8,9]$. The walls were composed of solid clay bricks and cement mortar arranged in single leaf running bond. The tests were carried out at the Technical University of Catalonia (UPC).

The bricks were scaled to 1:4 of the full brick dimensions and the mortar was produced using Cemex M-80 mortar with adjusted granulometry for the removal of the larger aggregates. As such, the bricks measured $72.5 \times 35.0 \times 12.5 \mathrm{~mm}^{3}$ and the joints were $2.5 \mathrm{~mm}$ thick. The walls were capped using a stiff reinforced concrete beam. The vertical pre-compression and the horizontal load were applied on this beam. The experimental setup for the shear tests is shown in Fig. 1. The figure illustrates the positioning of the vertical and horizontal presses as well as the LVDTs for measuring vertical and horizontal deformation, the former attached directly to the wall and the latter measuring the movement of the beam.

A number of different geometrical layouts were tested, all based on single leaf running bond masonry walls, shown in Fig. 2. The basic wall, consisting of sixteen courses in height and four units in length, was subjected to the widest range of vertical pre-compression levels. The remaining typologies were derived from the basic wall by varying the height and length of the structure. These walls were subjected to a single value of vertical stress level. Finally, a wall type with an opening was tested under six levels of vertical stress.

In addition to the different geometrical typologies tested, the basic wall typology was tested under different boundary conditions.

(a)

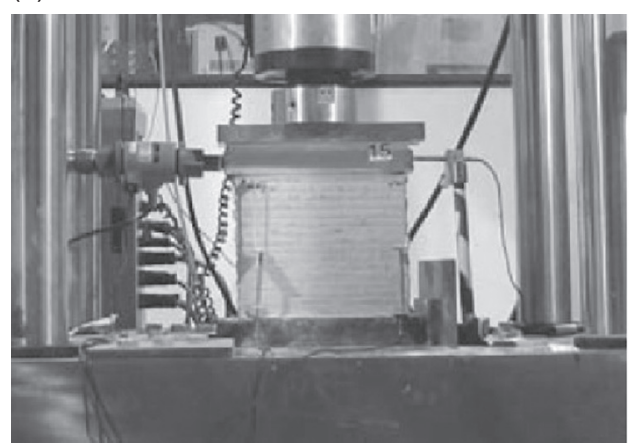

(b)

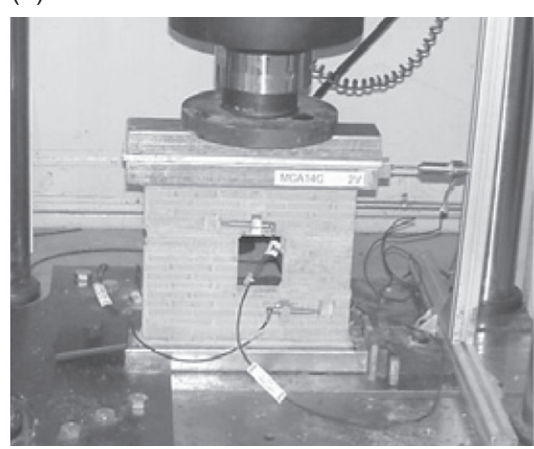

Fig. 1. Experimental setup for in-plane testing of wallettes under vertical pre-stress: (a) main series and (b) walls with opening. 
(a)

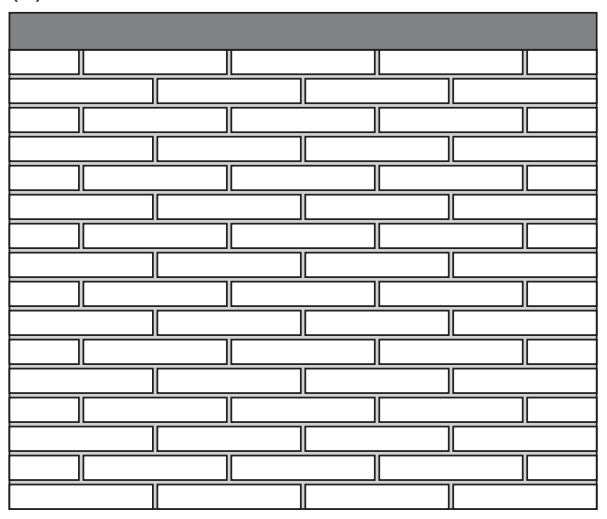

(c)

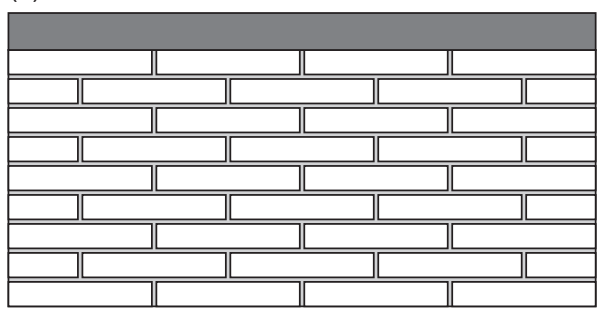

(b)

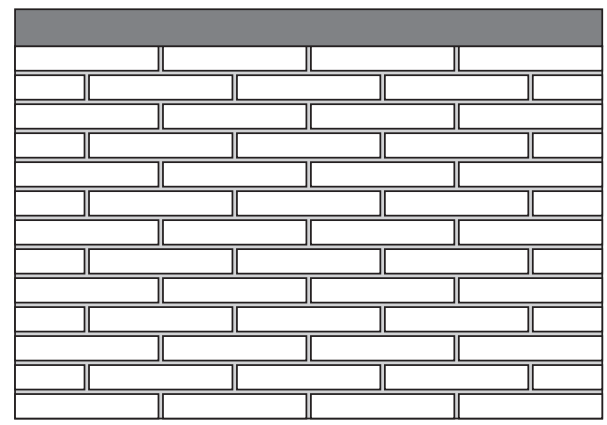

(d)

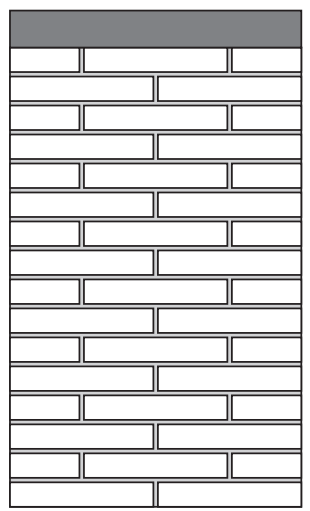

(e)

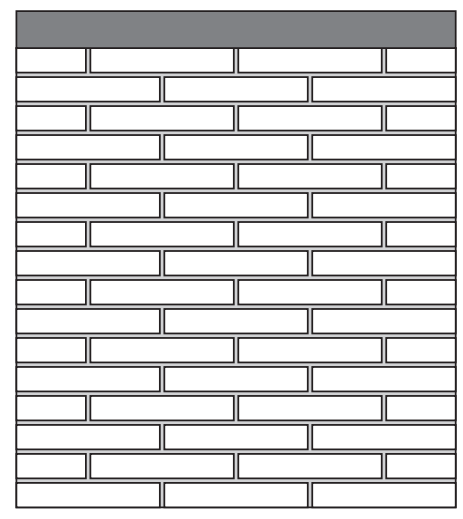

(f)

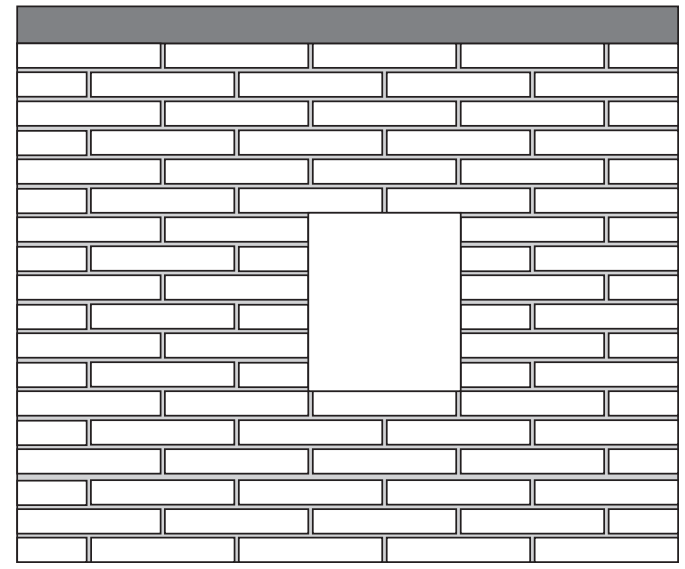

Fig. 2. Geometric layout of walls tested in shear: (a) basic wall, (b) \& (c) with variation in height, (d) \& (e) with variation in length and (f) wall with opening.

One series of tests was performed allowing full freedom of movement to the top bounding beam and one series with a beam restrained against rotation but left free to move vertically. The rest of the walls, including the walls with openings, were tested with free top bounding beams.

A single wall was tested for each value of vertical stress in the main series (free and constrained beam), two walls for each of the alternative dimension walls and one for each level of vertical stress for the walls with openings. Despite the use of a single data point for each vertical stress level for most of the series, the continuity of the data sets alleviates the risk of outlying results.

\subsection{Constituent materials}

\subsection{1. $1: 4$ scale units}

The units were solid clay bricks, measuring $72.5 \times 35.0 \times 12.5 \mathrm{~mm}^{3}$ in dimension. Rather than being produced by cutting full 
scale units to the desired dimensions, they were fabricated through the use of the same clayey paste used in the construction of regular clay bricks.

The compressive strength of the unit samples was determined through compression of the bricks in a direction perpendicular to the unit bed. The tests were carried out according to the relevant EN standard for the testing of masonry units [10]. This includes the application of a correction factor for the decrease of the apparent compressive strength of the unit due to the ratio of height to width.

Brick samples were also subjected to three-point bending tests. The tensile strength $\left(f_{t}\right)$ is derived from the experimentally determined flexural strength $\left(f_{f l e x}\right)$ through use of the equation proposed by the Model Code 2010 for concrete samples [11]:

$$
f_{t}=\frac{0.06 \cdot h^{0.7}}{1+0.06 \cdot h^{0.7}} f_{f l e x}
$$

The resulting tensile strength for the clay units is roughly equal to $10 \%$ the value of the compressive strength, which is a value compatible with empirical evidence.

The Poisson's ratios of the units were not directly measured, but were rather given nominal values.

\subsubsection{Micro-Mortar}

The mortar for the joints was especially designed to accommodate its placement in the thin joints. It is based on a Cemex M-80 mortar with an adjusted granulometry in order to remove the largest aggregates which could not be accommodated on the very thin mortar joints. Based on the elected scale factor, the resulting thickness of the mortar joints is $2.5 \mathrm{~mm}$. The achieved mean compressive strength of the samples was satisfactorily close to the desired $8.00 \mathrm{~N} / \mathrm{mm}^{2}$.

The mortar samples were produced and tested in three-point bending and compression according to the EN standard for masonry mortar testing [12]. The tensile strength of the samples was determined as per the clay unit samples.

Similarly to the case of the units, the Poisson's ratio was not directly measured.

\subsection{Small assemblies and wallettes}

\subsubsection{Masonry samples in shear}

Small masonry samples, in 1:4 scale, were used for the determination of the properties of the unit-mortar interface in shear and direct tension. For the frictional parameters shear tests were carried out on masonry wallettes subjected to shear under varying levels of normal stress [9], taking into account to the relevant EN standard [13], whereas the last parameter was determined through direct tension tests on couplets [14]. The fracture energy was not measured directly but was rather assumed according to semi-empirical rules and the study of the available inventory of experimental results [15].

\subsubsection{Masonry samples in compression}

Small masonry samples, in 1:4 scale and arranged in both running and stack bond configuration, were tested in compression [8]. The stack bond prisms were tested in the direction perpendicular to the bed joints, whereas the running bond wallettes were tested in the directions both parallel and perpendicular to the bed joints. For all tests the relevant EN standard was consulted and followed [16].

The influence of the existence of head joints in the behavior of masonry is apparent in the difference between the compressive strength of the running bond wallettes and the stack bond prism in vertical compression. Additionally, the horizontal compressive strength of the running bond wallette was higher than the one in the vertical direction. This fact reveals a good compaction of the mortar in the head joints, to a degree that is often not achieved in brick masonry.

The results of the mechanical characterization campaign for the scaled materials are presented in Table 1 . These were the parameters that were used for the numerical analysis of the wallettes in compression and the walls in shear.

\subsection{Quarter scale walls under in-plane shear}

All experimental results are summarized in Table 2 . The table provides the maximum average shear stress $\left(\tau_{\text {max }}\right)$ corresponding to each applied average compression stress $\left(\sigma_{n}\right)$. The results include the Young's modulus ( $E_{\text {vert }}$ ) of the walls as measured during the

Table 1

Summary of mechanical properties of materials and small masonry assemblages. Values in italics were not experimentally determined.

\begin{tabular}{|c|c|c|c|c|c|}
\hline & $\mathrm{f}_{\mathrm{c}}\left[\mathrm{N} / \mathrm{mm}^{2}\right]$ & $\mathrm{f}_{\text {flex }}\left[\mathrm{N} / \mathrm{mm}^{2}\right]$ & $\mathrm{f}_{\mathrm{t}}\left[\mathrm{N} / \mathrm{mm}^{2}\right]$ & $\mathrm{E}\left[\mathrm{N} / \mathrm{mm}^{2}\right]$ & $\mathrm{v}[-]$ \\
\hline Units & 35.0 & 15.2 & 3.95 & 4080 & 0.15 \\
\hline Mortar & 8.34 & 3.08 & 1.36 & 3500 & 0.20 \\
\hline Prism vertical & 20.2 & - & - & & - \\
\hline Wallette vertical & 15.2 & - & - & 4370 & - \\
\hline \multirow[t]{3}{*}{ Wallette horizontal } & 16.9 & - & - & - & - \\
\hline & $\mathrm{f}_{\mathrm{t}}$ & c & $\varphi$ & & \\
\hline & {$\left[\mathrm{N} / \mathrm{mm}^{2}\right]$} & {$\left[\mathrm{N} / \mathrm{mm}^{2}\right]$} & {$[-]$} & & \\
\hline Unit-mortar Interface & 0.55 & 0.42 & $39^{\circ}$ & & \\
\hline
\end{tabular}


Table 2

Experimental results of quarter scale walls subjected to in-plane shear under vertical pre-stress.

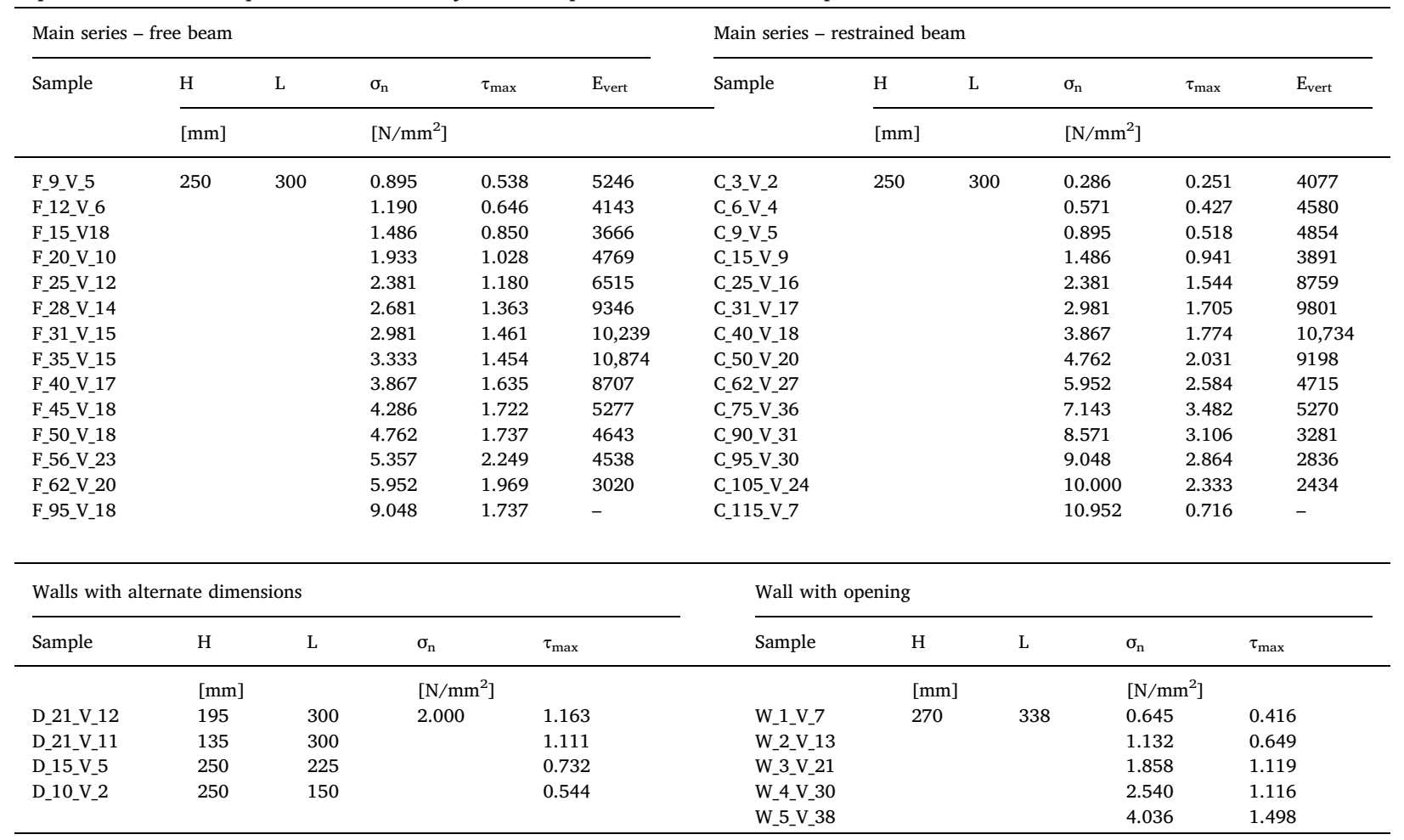

application of the vertical stress and the maximum shear for vertical stresses higher than $1.0 \mathrm{~N} / \mathrm{mm}^{2}$. Of note is the wide dispersion of the results of the vertical Young's modulus of the walls within each series. The overall average is $36 \%$ higher than the Young's modulus measured in the wallette tests, but with a high coefficient of variation of $45 \%$. The difference in the Young's modulus for different levels of applied stress could be attributable to the compaction of the bed joints under the effect of vertical stress. For higher levels the wall stiffens due to this compaction, while for the highest levels the drop in stiffness could be attributable to the beginning of hardening in compression.

Examples of the experimentally derived failure modes are shown in Fig. 3. In the main series of walls for an increase in the vertical stress level the failure mode shifted from a rocking mode dominated by opening of a flexural interface crack, to a shear sliding mode and finally to a diagonal cracking mode accompanied by crushing of the compressed toe.

The results of the walls with differing dimensions present a few interesting points for comparison with the main series of results. A decrease in height results in a small increase in maximum shear. A decrease in length, however, results in a significant decrease of the maximum shear stress.

The walls with the openings tended to produce a slightly lower maximum shear stress than the main series of walls with a free beam for the same value of vertical stress.

\section{Numerical modeling}

\subsection{Overview}

The numerical modeling effort primarily focuses on the simulation of the quarter scale wall models subjected to in-plane loading under varying levels of vertical pre-stress. A complementary set of analyses were carried out in order to simulate the tests on wallettes subjected to compression.

\subsection{Modeling approach}

For the finite element simulation of the experiments, a detailed micro-modeling approach is adopted. In this approach, the different constituent parts of the masonry composite are modeled individually: the units, the mortar and the unit-mortar interface. This approach is accompanied by a set of distinct advantages and disadvantages. Among the advantages one may include the direct anticipation of all expected failure modes that may arise in masonry under complex loading: tensile failure in the unit-mortar interface or in the units, shear sliding in the unit mortar interface, compressive failure of the mortar under multi-axial stress etc. 


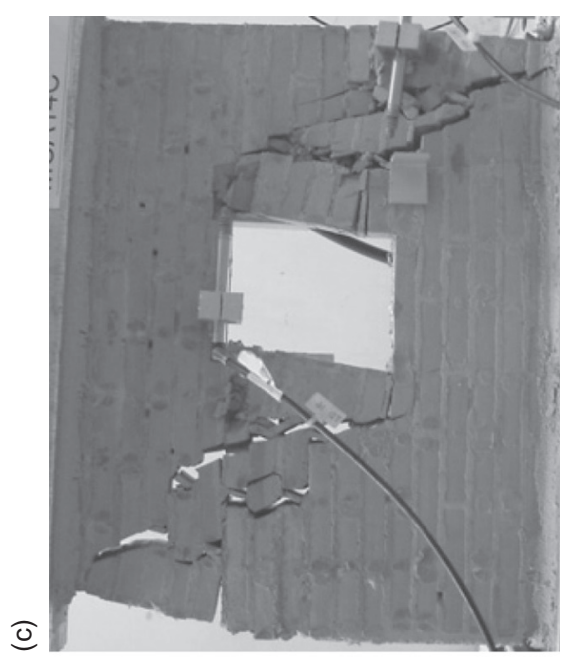

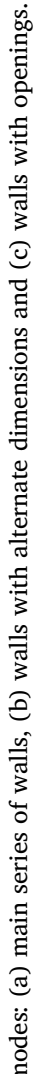
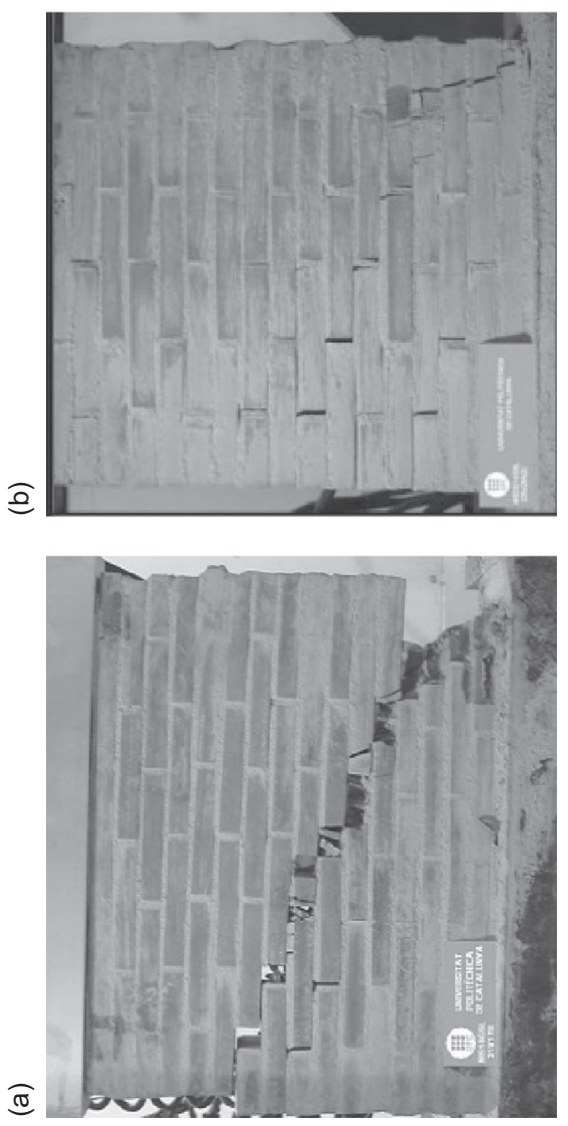

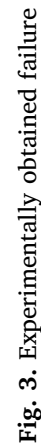


Additionally, it allows for a complete geometric representation of the physical object being modeled, introducing the least amount of geometric simplification or abstraction. Finally, the required input data consists of individual component properties (such as the compressive strength of bricks and masonry). Therefore, tests on large-size composite samples (such as triplets or wallets), which are more difficult to carry out, especially in the case of existing masonry, are not necessary. Among the disadvantages are the complexity of the geometry of the models and the significant computational cost compared to, for example, macro-modeling approaches. The DIANA FEA program was employed for the computations [17].

For the three dimensional meshes 20-node brick elements and 16-node interface elements were used. The plane models were created using 8-node continuum elements and 6-node interface elements.

The continuum elements were assigned nonlinear elastic properties. For the simulation of yielding in tension and compression a total strain crack modeling approach was adopted [18] using exponential softening in tension and parabolic hardening with ideally plastic post-peak behavior in compression [19]. The behavior of the mortar under biaxial or triaxial compression is governed by the Hsieh-Ting-Chen failure criterion [20]. The failure criterion reads:

$$
f=C 1 \frac{J_{2}}{f_{c}^{2}}+C 2 \frac{\sqrt{J_{2}}}{f_{c}}+C 3 \frac{f_{c 1}}{f_{c}}+C 4 \frac{I_{1}}{f_{c}}-1
$$

where $I_{1}$ and $J_{2}$ are the stress invariants, $f_{c}$ is the uniaxial compressive strength, $f_{c 1}$ is the maximum principal stress. The confinement afforded on the mortar in the joints by the units may result in a significant increase of its apparent compressive strength. The failure surface was defined according to the numerical parameters used for concrete under multi-axial stress: (a) a tensile strength equal to 0.10 times the uniaxial compressive strength, (b) a biaxial compressive strength of 1.15 times the uniaxial compressive strength, and (c) a compressive strength equal to 4.20 times the uniaxial compressive strength, under biaxial pressure equal to 0.80 times the uniaxial compressive strength. The interfaces were prescribed a Mohr-Coulomb failure criterion in shear, combined with a Rankine criterion in tension.

(a)

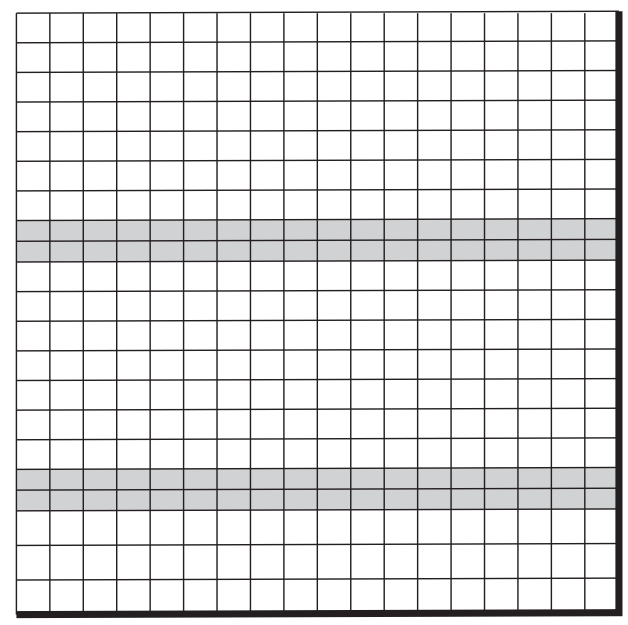

(b)

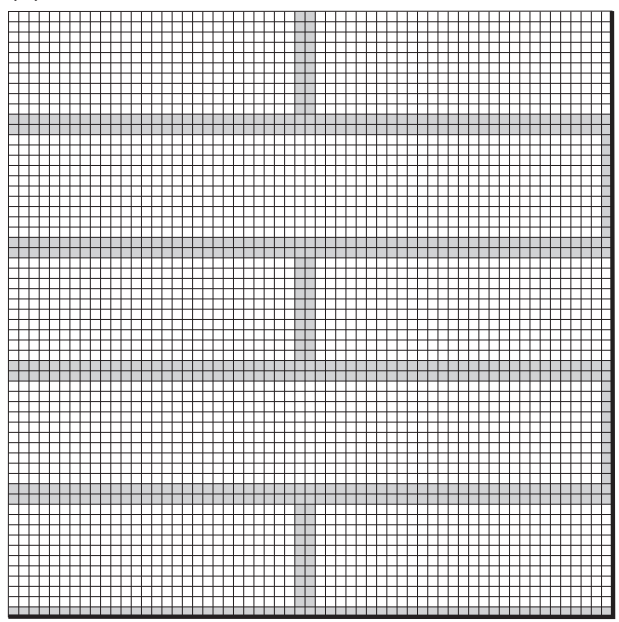

(c)

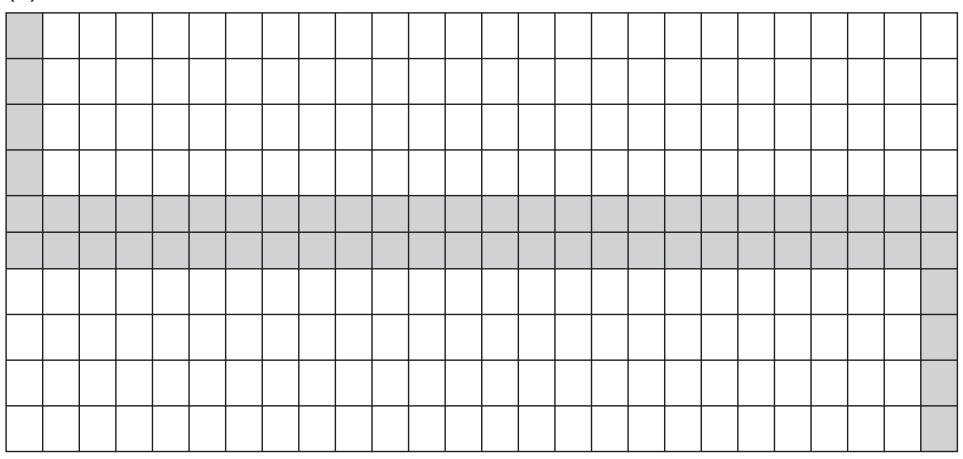

Fig. 4. Finite element meshes for compression test simulation: (a) stack bond prism, (b) running bond wallette and (c) periodic unit cell. Symmetry planes in (a) and (b) indicated by tinted lines. 


\subsection{Compression test analyses}

The masonry composites of running bond wallettes and stack bond prisms were modeled and subjected to uniaxial compression. In addition to the use of full finite element models for the simulation of the compression tests on the running bond wallettes, models of the periodic unit cell of the masonry were additionally elaborated, imposing the appropriate periodic boundary conditions, and subjected to the same load.

The FE meshes used for the preliminary analyses on the compressive strength of masonry are shown in Fig. 4. For the prism model 3402 solid elements were used, for the wallette 20,886 solid and 3582 interface elements and for the cell 3120 solid and 672 interface elements. The compressive loads were applied as uniform displacements at the compressed face of the model. Planes of symmetry were considered wherever possible in order to minimize the size of the models and the expended computational effort. For the cell model displacement conformity conditions were applied at the edges of the cell in order to ensure uniform displacement of the faces.

The numerical results for the prism and wallettes subjected to uniaxial compression are presented in Table 3. In terms of the predicted Young's modulus of masonry, the full wallettes and the cells give very similar results. As expected, no difference was registered in the Young's modulus of masonry due to interface nonlinearities. The prism in vertical compression has the highest strength, followed by the wallette in vertical compression and, finally, the wallette in horizontal compression. The influence of the interface nonlinearities on the compressive strength of the wallettes is stronger in the horizontal direction, where a $10 \%$ drop in the compressive strength was registered when they are taken into account. For the cell models a 13\% drop in the compressive strength was registered in the vertical direction. Despite this relatively small effect on the compressive strength of masonry, interface nonlinearities should always be taken into account when investigating the behavior of masonry in tension and shear.

In general, the FE models give a good approximation of the experimentally derived compressive strength and Young's modulus. The cell models give results similar to the full wallettes. The computational cost for an analysis using the wallette model is significantly higher than for the cell model due to the smaller number of elements of the latter. Therefore, the analysis of masonry walls using cell models for the determination of their compressive strength can be seen as an efficient alternative to full wallette model simulations for the determination of the in-plane failure envelope of the masonry composite.

\subsection{Shear test analyses}

The finite element meshes of the shear walls are shown in Fig. 5. The face of each masonry unit was divided to $32 \times 6$ elements. All mortar joints have 2 elements across their thickness. Both two-dimensional models (plane strain and plane stress) and threedimensional ones were used to describe the walls. In the case of the three-dimensional models, 6 elements were used across the thickness of the walls. For the main series of walls 101,304 brick elements were used for the units and the mortar and 26,892 interface elements for the unit/mortar interfaces in the three-dimensional models. Since the plane stress and plane strain models used the same overall arrangement of finite elements, 16,884 surface and 4482 interface elements were used in both cases.

The vertical load is applied as a uniform stress at the top of the walls, kept constant throughout the analysis. The horizontal load is applied as a uniform displacement at the top, monotonically increasing.

\subsection{Plane vs. three-dimensional modeling}

As shown in Fig. 6, the three-dimensional models are able to reproduce the experimental results fairly accurately. In the case of the unrestrained wall there is nearly complete coincidence of experimental and numerical results for the entire range. In the case of the restrained walls, the radical change of trend in the experimental results for a vertical stress higher than $7.5 \mathrm{~N} / \mathrm{mm}^{2}$ was not registered, although a slight change of trend was indeed noticed for a vertical stress load higher than $8.5 \mathrm{~N} / \mathrm{mm}$.

The parametric investigation in the main series of walls consists in examining the effect of different stress and strain conditions on the obtained results. While, from a geometrical point of view, plane stress or plane strain modeling may seem initially acceptable as an alternative to three-dimensional modeling, the results may vary greatly between the various approaches as a result of the substantial difference in the confinement of the mortar under compression which they afford [15]. This is especially important for walls under in-plane shear for higher levels of vertical pre-stress or a restriction of the rotation of the upper bound of the wall, due to the response being dominated by the formation of the diagonal compressive strut.

The plane stress model, although giving adequate results for low levels of vertical stress, failed to accurately predict the maximum shear for the greatest part of the vertical stress range: the numerical values in this case were greatly underestimated. The low confinement afforded on the mortar by the units in the plane stress models did not allow for a vertical pre-stress higher than the

Table 3

Analysis results on wallettes in compression. Percentile difference from average experimental values in parentheses.

\begin{tabular}{|c|c|c|c|c|c|}
\hline Model & & $\mathrm{f}_{\mathrm{c}, \text { vert }}\left[\mathrm{N} / \mathrm{mm}^{2}\right]$ & $\mathrm{E}_{\mathrm{vert}}\left[\mathrm{N} / \mathrm{mm}^{2}\right]$ & $\mathrm{f}_{\mathrm{c}, \text { horz }}\left[\mathrm{N} / \mathrm{mm}^{2}\right]$ & $\mathrm{E}_{\mathrm{horz}}\left[\mathrm{N} / \mathrm{mm}^{2}\right]$ \\
\hline Prism & Meso-Model & $18.90(6.48 \%)$ & 3982 & - & - \\
\hline \multirow[t]{2}{*}{ Wallette } & Meso-Model & $16.21(6.43 \%)$ & 3917 (10.37\%) & $16.92(0.42 \%)$ & 3966 \\
\hline & Micro-Model & $16.08(5.58 \%)$ & 3917 (10.37\%) & $15.33(9.02 \%)$ & 3966 \\
\hline \multirow[t]{2}{*}{ Unit Cell } & Meso-Model & $16.9(10.97 \%)$ & $3982(8.88 \%)$ & $15.26(9.44 \%)$ & 3928 \\
\hline & Micro-Model & $14.74(3.22 \%)$ & $3982(8.88 \%)$ & $14.91(11.51 \%)$ & 3928 \\
\hline
\end{tabular}


(a)

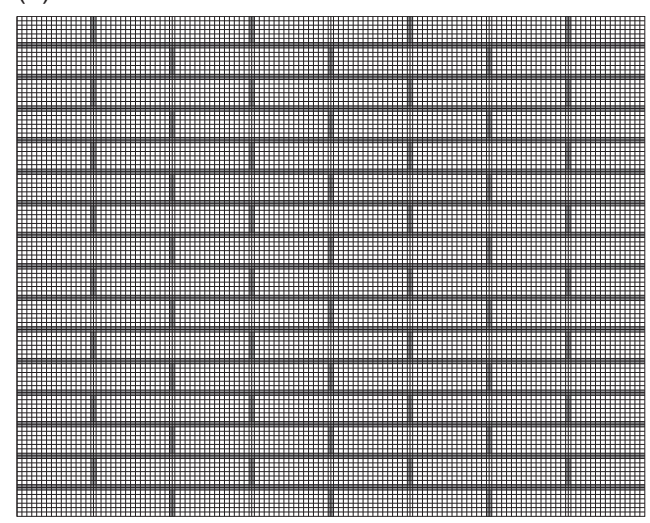

(c)

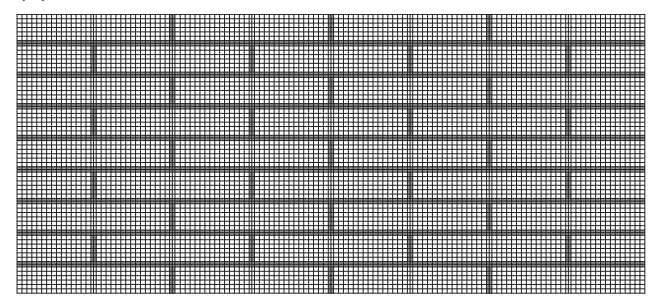

(e)

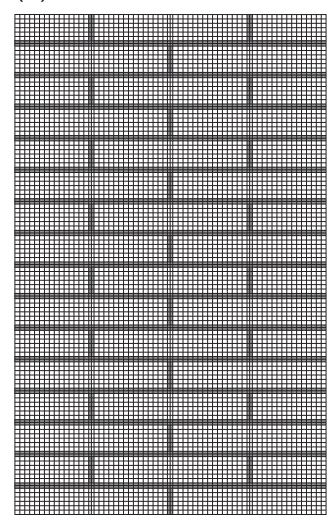

(b)

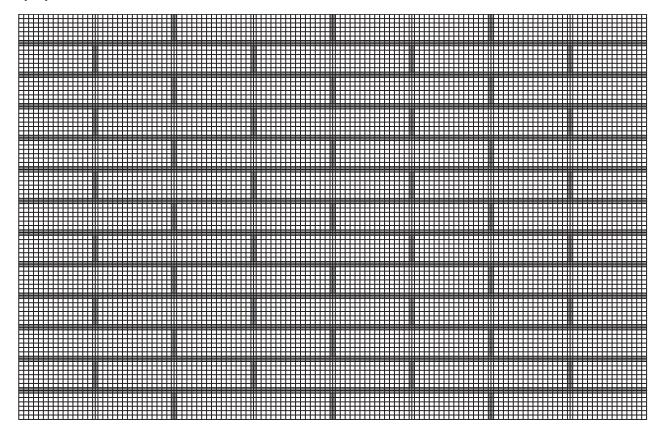

(d)

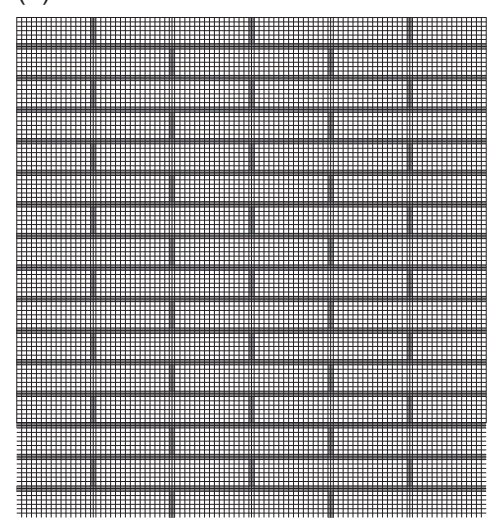

(f)

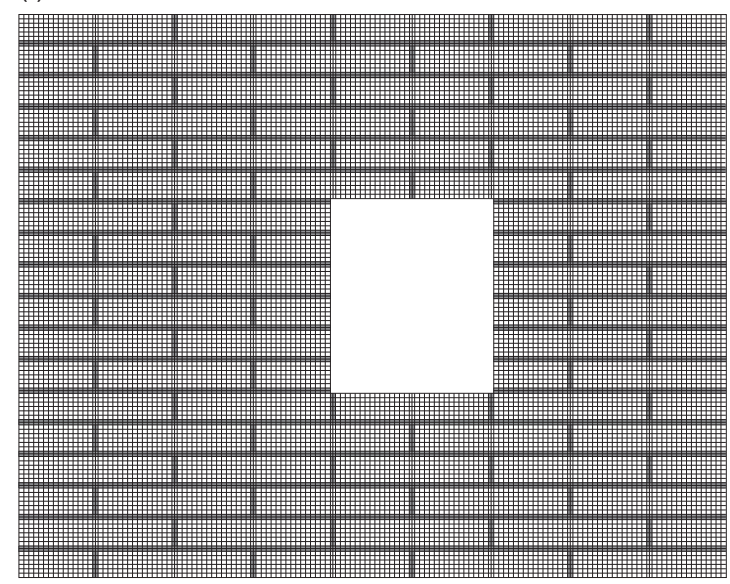

Fig. 5. Finite element meshes for in plane shear test simulation: (a) basic wall, (b) \& (c) with variation in height, (d) \& (e) with variation in length and (f) wall with opening.

uniaxial strength of the mortar to be applied on the walls. The plane strain model, however, provided very adequate results, with values very near those given by the three-dimensional model. For the highest range of the spectrum of vertical pre-stress, the plane strain model tended to slightly overestimate the maximum shear, while the three-dimensional model slightly underestimated it.

It has been already shown that plane strain models tend to provide values for the compressive strength of masonry higher than those of three-dimensional models, while plane stress models usually underestimate it [21]. Three-dimensional models normally provide results between the two plane approaches. In the case of the shear wall experiments here considered, the plane stress models again underestimate the experimental value of the maximum shear. The near coincidence of the results provided by the threedimensional and plane strain models indicates that in micro-modeling of shear walls the confinement effects in mortar under compression are critical but are not the only decisive factor for correctly predicting the shear capacity of masonry walls.

Overall, unlike the case of masonry under uniaxial compression, plane strain modeling proves practically equal to three- 
(a)

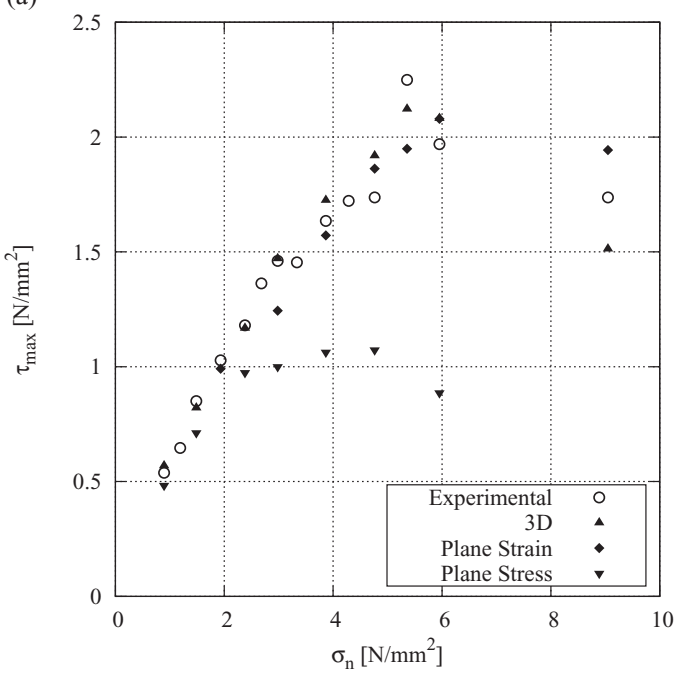

(b)

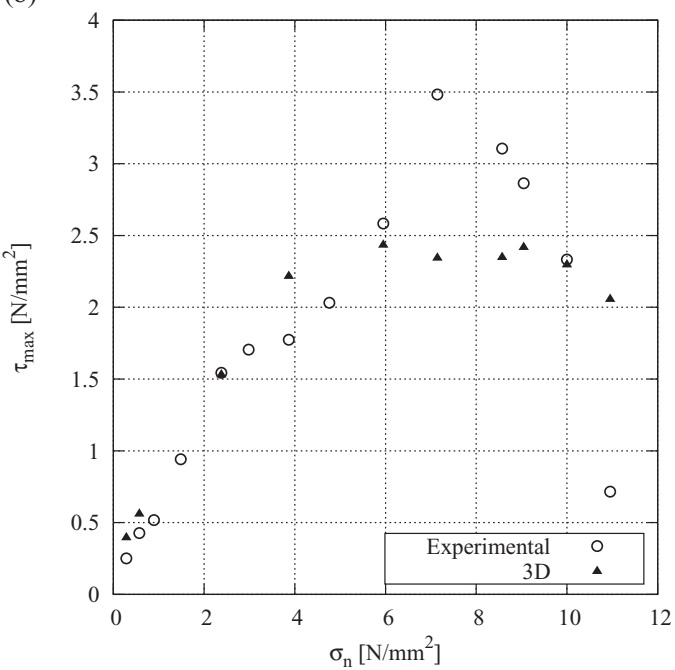

Fig. 6. Interaction diagrams and comparison of experimental with numerical results for series of main walls: (a) with free rotating top beam for different modeling assumptions and (b) with restrained top.

dimensional modeling for the purpose of predicting the capacity of walls in shear, while simultaneously being advantageous in terms of computational efficiency. Plane stress is an adequate choice for a very limited range of the spectrum of vertical stress levels in this particular sample of cases.

Fig. 7a shows the comparison of the maximum shear between the four walls with alternative dimensions and their numerical simulation. The agreement is very satisfactory in two of the cases, while some divergence is found for the remaining two. However, the trend of the variation of the maximum shear with the average compression level is correctly reproduced. Fig. $7 \mathrm{~b}$ shows the comparison of the experimental and numerical results for the series of walls with openings. The maximum shear predicted by the finite element model is generally in agreement with the experimental results, although the numerical model tends to underestimate the value for higher vertical compression levels.

Examining the shear stress/displacement graphs of the main series, a change in the ductility of the response of the walls is noted. For low levels of vertical stress, in which the failure is dominated by a rocking mode, the response is highly ductile. As the vertical stress increases there is a noted drop in ductility. This change of ductility is shown in Fig. 8, where for low levels of vertical stress the shear reaches a long plateau, whereas brittle behavior is noted for higher levels of vertical stress.

The shift in failure mode is also evident in the deformation and damage patterns obtained numerically for the same series of

(a)

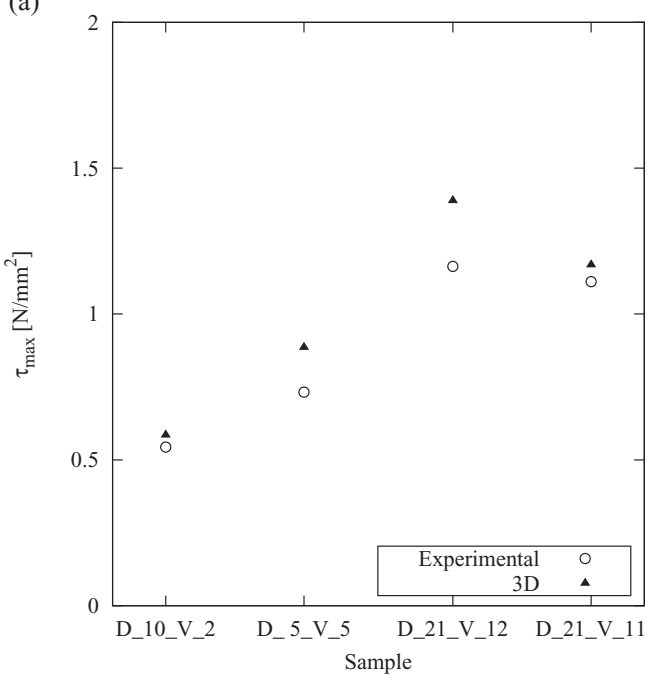

(b)

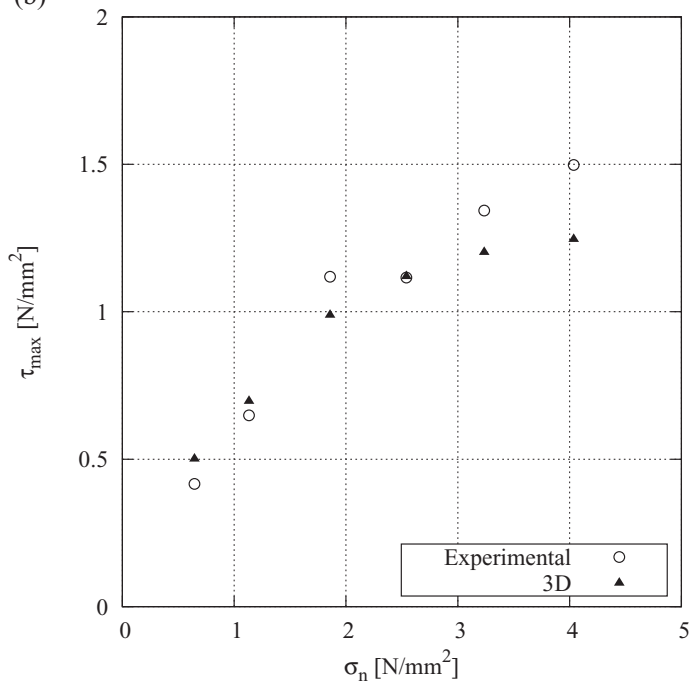

Fig. 7. Comparison of experimental with numerical results: (a) walls with alternate dimensions and (b) walls with opening for varying levels of vertical pre-stress. 


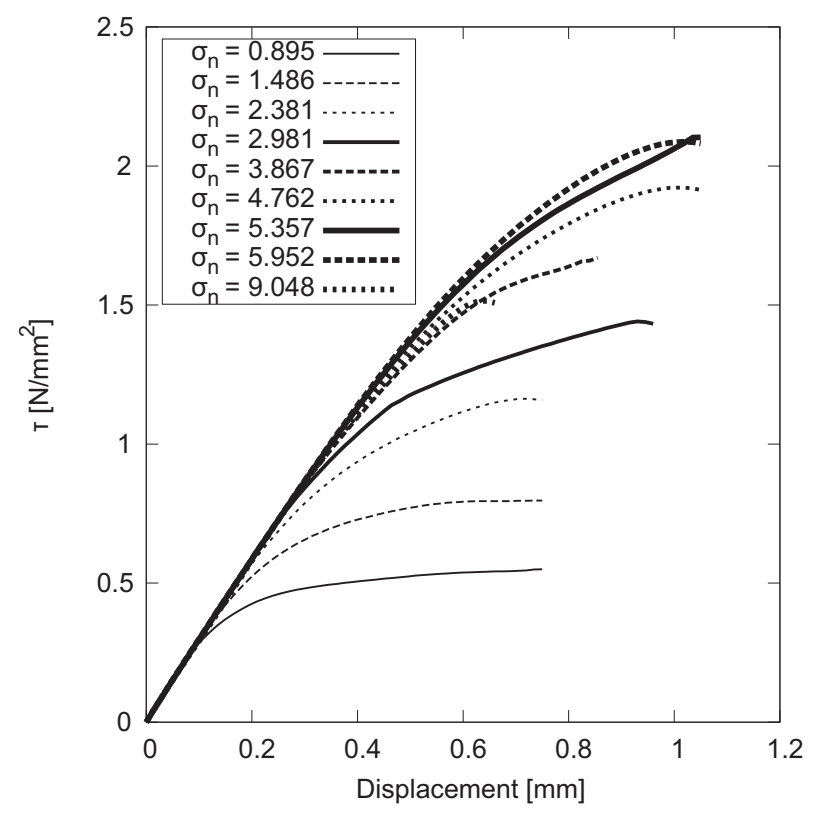

Fig. 8. Numerically derived shear stress-displacement graphs for main series of walls.

results. In Fig. 9a, the rocking failure mode is clearly shown by the opening of the bed joint interface at the lower-most course, accompanied by opening of the head joints at the compressed diagonal of the wall, particularly at mid height. Fig. $9 \mathrm{~b}$ shows some opening of the bed joint interface in the same location. However, shear sliding and cracking are additionally appearing across the compressed diagonal, along with crushing of the compressed foot. In Fig. 9c there is no opening of the bed joint interface and significant cracking takes place at the compressed foot, accompanied by yielding in compression.

\subsection{Comparison with closed form expressions}

The experimental and the finite element analysis results, focusing on the series of walls with unrestrained top, will be compared to the results obtained from closed form expressions and modern masonry design rules. These expressions, proposed for the solution of the same problem, rely on the determination of different material parameters for the masonry composite: its shear, tensile and compressive behavior.

A model based on the Mohr-Coulomb criterion for shear under applied normal stress is proposed by the EN standard for masonry design [22]. The maximum shear is equal to

$$
\tau_{\max }=c+0.4 \cdot \sigma_{n}
$$

where $\mathrm{c}$ is the initial shear strength and $\sigma_{\mathrm{n}}$ the applied normal stress, taking compressive values as positive. In this standard a value of $0.2 \mathrm{~N} / \mathrm{mm}^{2}$ may be prescribed for the initial shear strength for this masonry typology, which is not very different from the value of $0.25 \mathrm{~N} / \mathrm{mm}^{2}$ determined experimentally. The 0.4 value in the equation corresponds to the tangent of the friction angle as proposed in the standard for masonry in general, which is very different from the value of 0.81 determined in the experiments. While this expression accounts for only a shearing type failure of the wall, bending failure being taken into account through other expressions in the standard, it is included in this study in order to underline the phasing out of shearing failure under higher compressive loads.

A flexural model for masonry in shear, based on in-plane equilibrium of the shear wall and assuming a plastic distribution of compressive stresses in the compressed toe, has also been formulated, proposed by the Italian Ministry of Infrastructure and Transport [23]. According to this model the maximum shear is equal to

$$
\tau_{\max }=\frac{\sigma_{n} L}{2 H}\left(1-\frac{\sigma_{n}}{0.85 f_{c}}\right)
$$

where $\mathrm{f}_{\mathrm{c}}$ is the compressive strength of masonry, $\mathrm{H}$ is the height of shear wall and $\mathrm{L}$ is its length. In this case the compressive strength of masonry will be taken as equal to the average of the compressive strength determined in the running bond wallettes in the vertical and horizontal direction: $16.05 \mathrm{~N} / \mathrm{mm}^{2}$.

Finally, a model using the tensile strength of the masonry composite has been proposed by Turnšek \& Cacovic [4]. It assumes the formation of diagonal cracks in the masonry wall. The dimensions of the wall are not taken into account in the expression. According to this model the maximum shear is equal to 


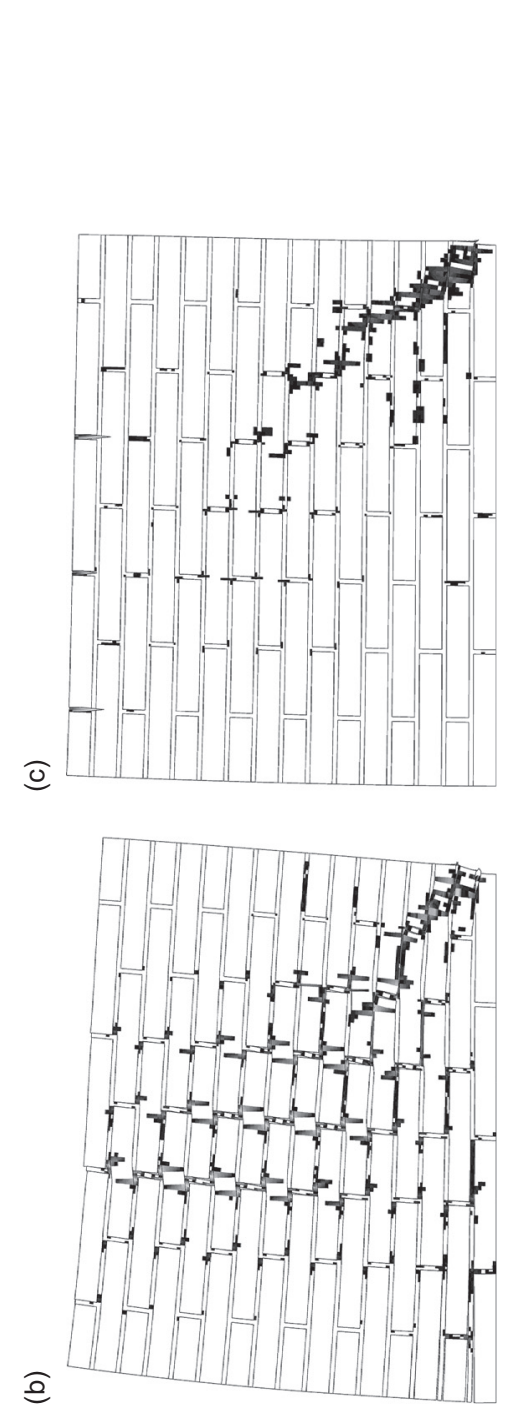

है
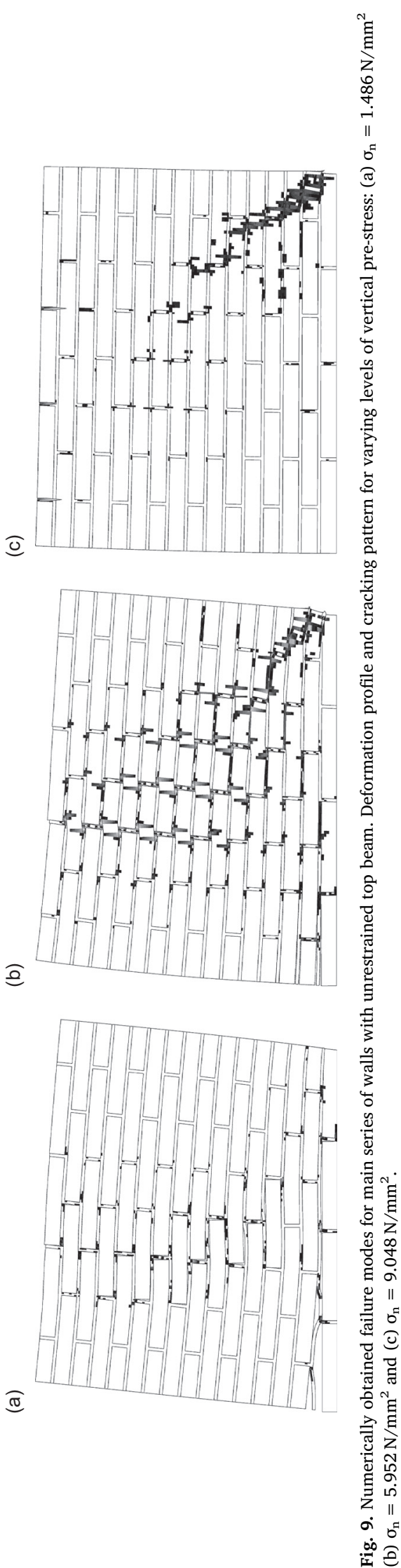


$$
\tau_{\max }=f_{t} \sqrt{1+\frac{\sigma_{n}}{f_{t}}}
$$

In this study the tensile strength of masonry $\mathrm{f}_{\mathrm{t}}$ will be taken as equal to the tensile strength of the unit/mortar interface. This value corresponds to $3.4 \%$ of the compressive strength of the masonry composite. This assumption is deemed reasonable in light of to the predominantly flexural response of the walls with an unrestrained top, which results in the opening of the bed joints.

The comparison of all the experiments and analysis approaches is shown in Fig. 10. According to the interaction diagram of applied normal stress vs. maximum shear it becomes apparent that the finite element models produce the most accurate results. Among the three analytical expressions studied the flexural model based on compressive strength produces the most accurate results, being behind in terms of accuracy only to the finite element model. However, due to the formulation used in the model, the shear strength of the wall for zero vertical load is zero as well. The EN standard expression, though based on a nominal friction angle and a prescribed cohesion based on the masonry typology, produces good results in the range of vertical stress between 0.5 and $3.0 \mathrm{~N} / \mathrm{mm}^{2}$. Its orientation as a design code makes it reasonably accurate in its intended spectrum of application: vertical stresses higher than $3.0 \mathrm{~N} / \mathrm{mm}^{2}$ are unlikely to arise in masonry walls under shear loading. However, its results diverge for higher levels of vertical stress. Finally, the model based on the tensile strength of masonry does not produce consistently satisfactory results for any part of the experimental range. Despite using a low value for the tensile strength (that of the unit/mortar interface) the model overestimates the maximum shear for a range of vertical stress between 0.0 and $3.0 \mathrm{~N} / \mathrm{mm}^{2}$.

Of the three analytical models investigated the one based on the compressive strength of masonry appears to provide the best overall results. This fact highlights the importance of properly modeling and taking into account the compressive strength of masonry in shear walls. Three-dimensional micro-models have already been proven to achieve good results in this regard, hence their good performance in simulating this series of experiments.

\section{Conclusions}

The analysis of masonry walls subjected to in-plane shear was attempted using detailed micro-models. The resulting maximum shear was for the most part accurately predicted by the models for a wide range of vertical pre-stress levels and different geometrical layouts.

The numerical analysis results proved far more accurate compared to closed form expressions and design guidelines. While the latter group of methods for predicting the maximum resisting force of shear walls provided good results for low levels of vertical prestress, the numerical approach provided more consistently accurate predictions.

The three-dimensional models produced results very similar to the plane strain approach, whereas the plane stress approach greatly underestimated the experimentally derived maximum shear. The equal adequacy of the first two approaches makes plane strain an attractive choice for the analysis of shear walls using detailed micro-modeling as its computational cost is significantly lower than the cost of full three-dimensional analysis.

The observations concerning the influence of the out-of-plane stresses in masonry under in-plane loading, highlighted by the inadequacy of plane stress models to accurately predict the maximum shear obtained in the experiments, are critical concerning the

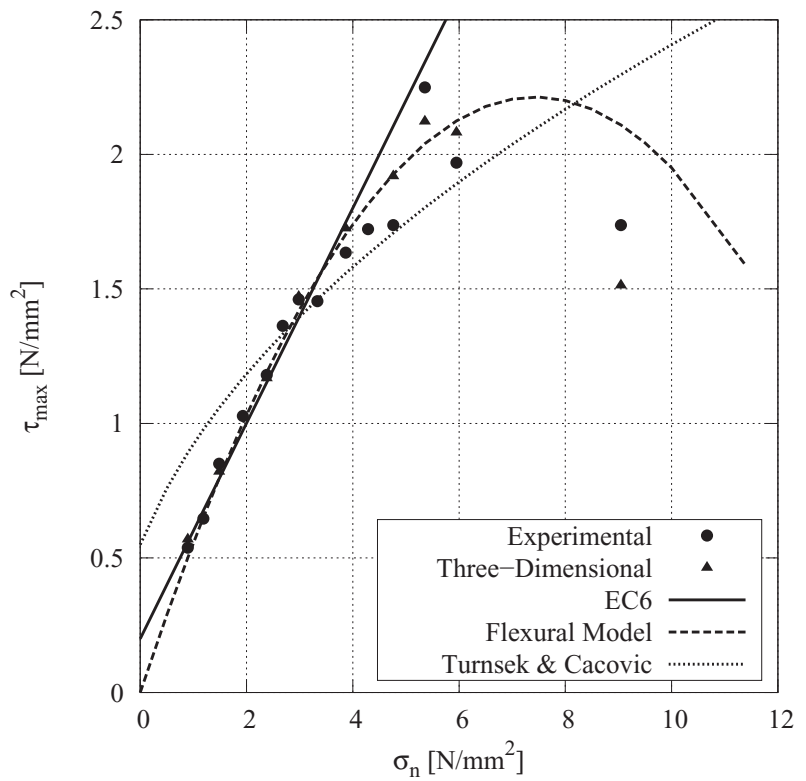

Fig. 10. Comparison of obtained peak shear stress: experimentally obtained vs. numerically and analytically derived values. 
numerical simulation of such problems. The simulation of the confined mortar in the joints is shown to be important not only in the simulation of masonry under pure compression but under in-plane shear as well, particularly in the case of high levels of vertical loads.

Concerning the prediction of the compressive strength of masonry using micro-models, significant agreement was found between the results obtained from the analysis of full wallettes and periodic unit cells, in addition to the results being in good agreement with the experimental findings. The latter models have a much lower computational cost and may serve as an efficient alternative to full wall models for the determination of the failure envelope of masonry wall structures. Finally, the influence of the nonlinearities of the unit/mortar interface on the compressive strength of masonry was investigated using finite element micro-models and meso-models. Only a small to moderate drop in the predicted compressive strength was found when considering interface nonlinearities, thus rendering their inclusion in such models of limited value.

\section{Acknowledgements}

The authors gratefully acknowledge the financial support from the MINECO (Ministerio de Economia y Competitividad of the Spanish Government) and the ERDF (European Regional Development Fund) through the MULTIMAS project (Multiscale techniques for the experimental and numerical analysis of the reliability of masonry structures, ref. num. BIA2015-63882-P).

\section{References}

[1] A. Penna, P. Morandi, M. Rota, C.F. Manzini, F. Da Porto, G. Magenes, Performance of masonry buildings during the Emilia 2012 earthquake, Bull. Earthq. Eng. 12 (2013) 2255-2273, https://doi.org/10.1007/s10518-013-9496-6.

[2] G. Magenes, G.M. Calvi, In-plane seismic response of brick masonry walls, Earthq. Eng. Struct. Dyn. 26 (1997) 1091-1112.

[3] H.R. Ganz, B. Thürlimann, Strength of brick walls under normal force and shear. 8th, Int. Symp. load Bear. brickwork (1983) $27-29$.

[4] V. Turnšek, F. Cacovic, Some experimental results on the strength of brick masonry walls, Proc. 2nd Intern. Brick Mason. Conf, 1971, pp. 149-156.

[5] F.Y. Yokel, S.G. Fattal, Failure hypothesis for masonry shear walls, J. Struct. Div. 102 (1976) 515-532.

[6] L. Pelà, M. Cervera, P. Roca, An orthotropic damage model for the analysis of masonry structures, Constr. Build. Mater. 41 (2013) 957-967, https://doi.org/10. 1016/j.conbuildmat.2012.07.014.

[7] P. Roca, M. Cervera, G. Gariup, L. Pelà, Structural analysis of masonry historical constructions. Classical and advanced approaches, Arch Comput Methods Eng 17 (2010) 299-325, https://doi.org/10.1007/s11831-010-9046-1.

[8] J.A. Charry Ablanque, Estudio Experimental del Comportamiento de Paredes de Obra de Fábrica de Ladrillo ante la Acción de Cargas Laterales, Department of Strength of Materials and Structural Engineering, Technical University of Catalonia, Barcelona Spain, 2010 PhD dissertation.

[9] E.M. Lobato Paz, Método simple para el análisis de muros de obra de fábrica con aberturas bajo solicitaciones en su plano, Department of Strength of Materials and Structural Engineering, Technical University of Catalonia, Barcelona Spain, 2009 PhD dissertation.

[10] CEN, EN 772-1 - Methods of Test for Masonry Units. - Part 2: Determination of Compressive Strength, (2011).

[11] Federátion Internationale du Béton, The fib Model Code for Concrete Structures 2010, (2013).

[12] CEN. EN 1015-11, Methods of test for mortar for masonry - Part 11: Determination of flexural and compressive strength of hardened mortar, (2007).

[13] CEN. EN 1052-3, Methods of Test for Masonry - Part 3: Determination of Initial Shear Strength, (2002).

[14] C. Sandoval Mandujano, P. Roca, E. Bernat, L. Gil, Testing and numerical modelling of buckling failure of masonry walls, Constr. Build. Mater. 25 (2011) 4394-4402, https://doi.org/10.1016/j.conbuildmat.2011.01.007.

[15] A. Drougkas, P. Roca, C. Molins, Numerical prediction of the behavior, strength and elasticity of masonry in compression, Eng. Struct. 90 (2015) 15-28, https:// doi.org/10.1016/j.engstruct.2015.02.011.

[16] CEN. EN 1052-1, Methods of test for Masonry - Part 1: Determination of Compressive Strength, (1999).

[17] TNO, DIANA User's Manual. Delft: TNO DIANA BV, (2012).

[18] R.G. Selby, F.J. Vecchio, Three-dimensional constitutive relations for reinforced concrete, University of Toronto. Department of Civil Engineering (1993) 147 Publication number: 93-02.

[19] P.H. Feenstra, R. Borst, De. A composite plasticity model for concrete, Int. J. Solids Struct. 33 (1996) $707-730$.

[20] S.S. Hsieh, E.C. Ting, Chen WF. A plastic-fracture model for concrete, Int. J. Solids Struct. 18 (1982) $181-197$.

[21] A. Drougkas, P. Roca, C. Molins, Micro-Modeling of Stack Bond Masonry in Compression Using a Plasticity Law. 12th Int. Conf. Comput. Plast. Barcelona, Spain, (2013).

[22] CEN. EN 1996-1-1, Eurocode 6: Rules for Reinforced and Unreinforced Masonry, (2005).

[23] Italian Ministry of Infrastructure and Transport, Circolare 2 febbraio 2009, n. 617 Istruzioni per l'applicazione delle "Nuove norme tecniche per le costruzioni" di cui al decreto ministeriale 14 gennaio 2008, (2009). 